\title{
ELIGIBILITY FOR THE HIP-RESURFACING ARTHROPLASTY PROCEDURE: AN EVALUATION ON 592 HIPS
}

Roberto Dantas Queiroz', Rafael Salomon Silva Faria², David Marcelo Duarte², Marcelo Itiro Takano ${ }^{3}$, Maurício Morita Sugiyama ${ }^{4}$

\begin{abstract}
Objective: To investigate the percentage of ideal patients who would be eligible for hip-resurfacing surgery at a reference service for hip arthroplasty. Methods: Out of all the cases of hip arthroplasty operated at Hospital do Servidor Público Estadual de São Paulo (HSPE) between January 2009 and December 2010, we assessed a total of 592 procedures that would fit the criteria for indication for resurfacing arthroplasty, after clinical and radiological evaluation according to the criteria established by the Food and Drug Administration (FDA) and
\end{abstract}

by Seyler et al. Results: Among the total number of hip replacement arthroplasty cases, $5.74 \%$ of the patients were eligible. Among the patients who underwent primary arthroplasty, we found that $8.23 \%$ presented ideal conditions for this procedure. Conclusion: The study demonstrated that this type of surgery still has a limited role among hip surgery methods.

Keywords - Arthroplasty, Replacement, Hip; Femoral Neck Fractures; Femoral Head

\section{INTRODUCTION}

In the $1950 \mathrm{~s}$, John Charnley apud Seyler et al ${ }^{(1)}$ introduced what can be considered to be the first concept of resurfacing arthroplasty, using implants made from Teflon ${ }^{\circledR}$. The idea was abandoned because of disastrous results early on. At the end of the 1980s, another attempt at resurfacing was made by Wagner, using a metal-to-metal contact surface. Resurfacing was then only reintroduced at the end of the 1990s, with advances in tribology. Nonetheless, there is still much discussion in the medical literature regarding its real indication. On the other hand, it is known that the clinical results are extremely dependent on good patient selection $^{(2-7)}$ and on the details of the surgical technique ${ }^{(4,8-11)}$. According to the criteria currently used, it is seen that only a small percentage of the patients would be candidates for this technique. This is a matter for concern, given the long learning curve required for this procedure to be performed. According to Nunley et $a l^{(12)}$, the learning curve for avoiding early postoperative complications involves at least 25 procedures, and to achieve good postoperative radiographic parameters, 75 to 100 procedures. In this light, we conducted the present study with the aim of ascertaining the eligibility of patients who could undergo hip-resurfacing arthroplasty (HRA) in our setting and, through this, to investigate the viability of capacitating hip surgeons to perform this technique.

\section{OBJECTIVE}

The aim of this study was to quantify the number of patients who might have been eligible for the technique of HRA at the Orthopedics and Traumatology Clinic of the State Public Servants' Hospital (Hospital do Servidor Público Estadual, HSPE) in the years 2009 and 2010, out of a total of 592 hips that underwent hip arthroplasty.

\footnotetext{
1 - Head of the Orthopedics and Traumatology Clinic and Head of the Hip Group, HSPE-IAMSPE, São Paulo, SP, Brazil.

2 - Resident in Orthopedics and Traumatology, HSPE-IAMSPE, São Paulo, SP, Brazil.

3 - Attending Orthopedist in the Hip Group, HSPE-IAMSPE, São Paulo, SP, Brazil.

4 - Orthopedist and Specialist in Hip Surgery at HSPE-IAMSPE, São Paulo, SP, Brazil.

Work performed at the Orthopedics Study Center, State Public Servants' Hospital (HSPE), São Paulo

Correspondence: Rua Borges Lagoa 1755, 1 andar, sala 180, Vila Clementino, 04038-034 São Paulo, SP. E-mail: davidmarceloduarte@hotmail.com

Work received for publication: August 9, 2011; accepted for publication: October 4, 2011.
}

The authors declare that there was no conflict of interest in conducting this work 


\section{MATERIAL AND METHOD}

A survey of all the orthopedic surgical procedures performed between January 2009 and December 2010 at HSPE was conducted. Among these, there were 592 hip arthroplasty procedures, of which $41 \%$ were on male patients and $59 \%$ on female patients. The patients' mean age was 60.3 years, with a range from 27 to 98 years. Through our database, we were able to initially screen the patients to exclude those for whom HRA would not be applicable because of the presence of femoral neck fractures, and also those who underwent hip revision arthroplasty, totaling $139(23 \%)$ and $40(7 \%)$ of the patients respectively (Figure 1).

The second step of our investigation consisted of a clinical evaluation, by means of reviewing the medical files, and a radiographic evaluation, through assessing radiographic examinations in anteroposterior and lateral views on all the hips that had been operated using the standard technique. These examinations were all performed within the last preoperative month. In reviewing the medical files, we looked for data on previous pathological conditions such as neuromuscular and vascular diseases, diagnoses of osteoporosis or family histories of this, kidney failure (also assessed through preoperative examinations), obesity, acquired immunodeficiency syndrome, chronic use of corticoids or other immunosuppressants, or hip diseases during childhood. The assessments on the radiographic examinations consisted of quantifying the extent to which the femoral head was compromised in cases of osteonecrosis, the presence of cysts and their sizes, the presence of osteoporosis, assessed according to parameters defined by Singh et al $l^{(13)}$ (such that cases classified as grade 3 or lower were classified as osteoporosis), dysplastic abnormalities of the hip, signs of femoroacetabular impact and presence of Legg-Calvé-Perthes disease. Access to the radiographs was possible through images retrieved from the digitized system for imaging examinations at HSPE. The assessments on the medical files and radiographic examinations were done in conjunction by two residents of orthopedics and traumatology at HSPE, one orthopedist who was a specialist in hip surgery and two experienced hip surgeons.

In this second stage, among the 413 patients who remained, we applied the criteria for contraindication of HRA of the United States Food and Drug Administration (FDA) ${ }^{(14,15)}$. These criteria involved the following clinical parameters: active infection in the organism; skeletal immaturity; clinical situations presented by patients that might compromise the stability of the implant (muscle atrophy, neuromuscular diseases and vascular insufficiency); women of fertile age (limit of 45 years); kidney failure; severe obesity (body mass index greater than $40 \mathrm{~kg} / \mathrm{m}^{2}$ ); patients with immunological depression (due to acquired immunodeficiency syndrome, use of corticoids at immunosuppressant doses or use of other immunosuppressant agents); and known sensitivity to metal. The radiographic parameters included: osteoporosis; osteonecrosis affecting more than $50 \%$ of the femoral head; multiple cysts or cysts larger than $1 \mathrm{~cm}$; questionable bone stock, defined as bone mineral density lower than $0.65 \mathrm{~g} / \mathrm{cm}^{2}$ or a T-score lower than -1 on bone densitometry ${ }^{(16)}$ (Table 1). At this stage, 292 patients presented contraindications according to the FDA criteria. The main contraindications among females were osteoporosis (the most prevalent contraindication) (Figure 1), use of immunosuppressants (particularly in cases of rheumatoid arthritis) and fertile age. Among males, the main contraindications were cases of a compromised femoral head (more than $50 \%$ affected), with or without associated multiple cysts larger than $1 \mathrm{~cm}$; and osteoporosis. There were no cases relating to allergy to metal or cases of infection.

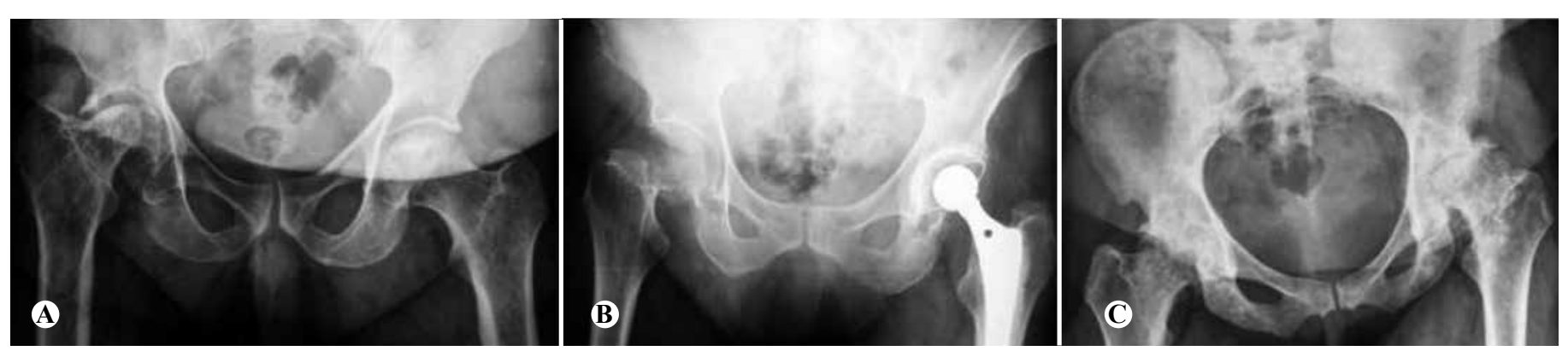

Figure 1 - (A) compromising of the femoral head greater than 50\%; (B) femoral neck fracture; (C) multiple cysts. 
After the exclusions made in the second stage, 121 patients remained. Through the data already gathered and from our database of radiographic examinations, we placed each patient individually in the algorithm proposed by Seyler et al $l^{(1)}$ (Figure 2). This algorithm was created with the objective of allowing both novice and experienced surgeons to reduce the complications associated with the procedure and improve the clinical results, i.e. to select ideal patients. The majority of the contraindications contained in the algorithm are

Table 1 - Contraindications against hip resurfacing arthroplasty according to the FDA.

\begin{tabular}{l}
\hline Infection of the organism \\
\hline Skeletal immaturity \\
\hline Clinical situation presented by the patient that might compromise \\
implant stability \\
- Muscle atrophy \\
- Neuromuscular diseases \\
Inadequate bone quality for supporting the implant \\
- Severe osteopenia or osteoporosis \\
- Osteonily history of severe osteoporosis or severe osteopenia \\
of Ficat stage) \\
- Multiple cysts on the femoral head (> 1 cm) \\
denstionable bone stock (surgeon should order a bone \\
\hline Women of fertile age \\
\hline Kidney failure (renal function tests are required, including the \\
glomerular filtration rate for creatinine and blood urea-nitrogen) \\
\hline Severe obesity \\
\hline Suppression of the immunological system due to diseases such \\
as acquired immunodeficiency syndrome (AIDS) or high doses of \\
corticosteroids and/or immunosuppressants \\
\hline Known sensitivity to metals \\
\hline
\end{tabular}

similar to those of the FDA, although Seyler emphasizes that it would be more prudent for surgery on the following types of cases to be avoided by inexperienced surgeons: patients at the age extremities $(<35$ and $>65$ years for men; and $<35$ and $>55$ years for women) and cases of inflammatory arthritis, dysplasia, femoroacetabular impact, bone metabolism diseases, compromised head ( $>35 \%$ in relation to Perthes) or osteonecrosis of the femoral head.

At the end of the study, we were able to set up an organogram providing an explanation of the assessment stages, as shown in Figure 3. In the first stage, it shows the exclusion of patients who underwent revision arthroplasty and those with femoral neck fractures; in the second stage, the exclusion of patients who did not meet the FDA criteria; and in the third stage, the exclusion of patients who, despite being eligible according to the FDA criteria, were not eligible according to the Seyler criteria.

\section{RESULTS}

Only $5.74 \%$ of the total number of arthroplasties performed at HSPE would have been ideal candidates for resurfacing between January 2009 and December 2010. From assessing only the cases of primary hip arthroplasty, only $8.23 \%$ out of the total of 413 procedures would have been candidates for HRA (Figures 4 and 5).

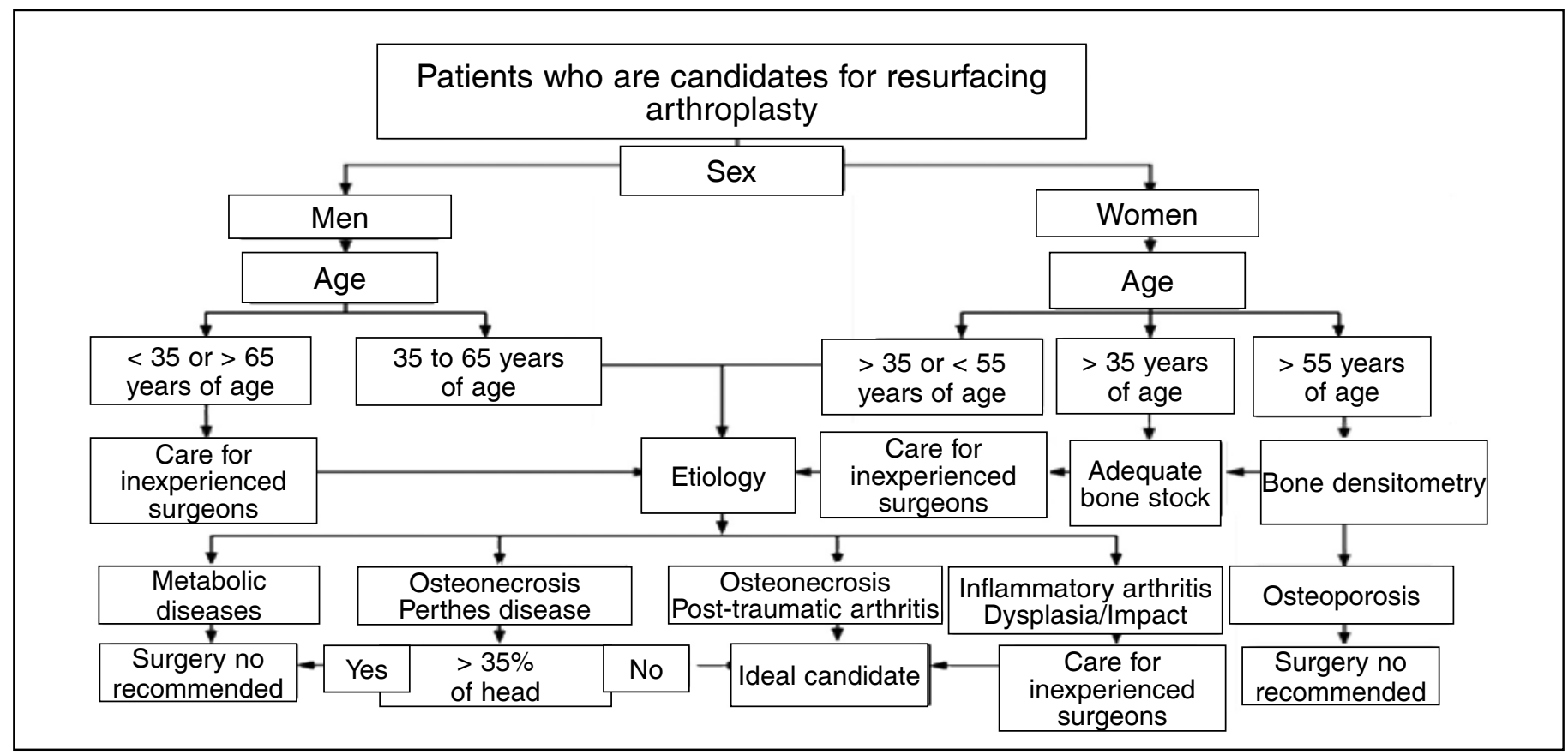

Figure 2 - Seyler algorithm. 


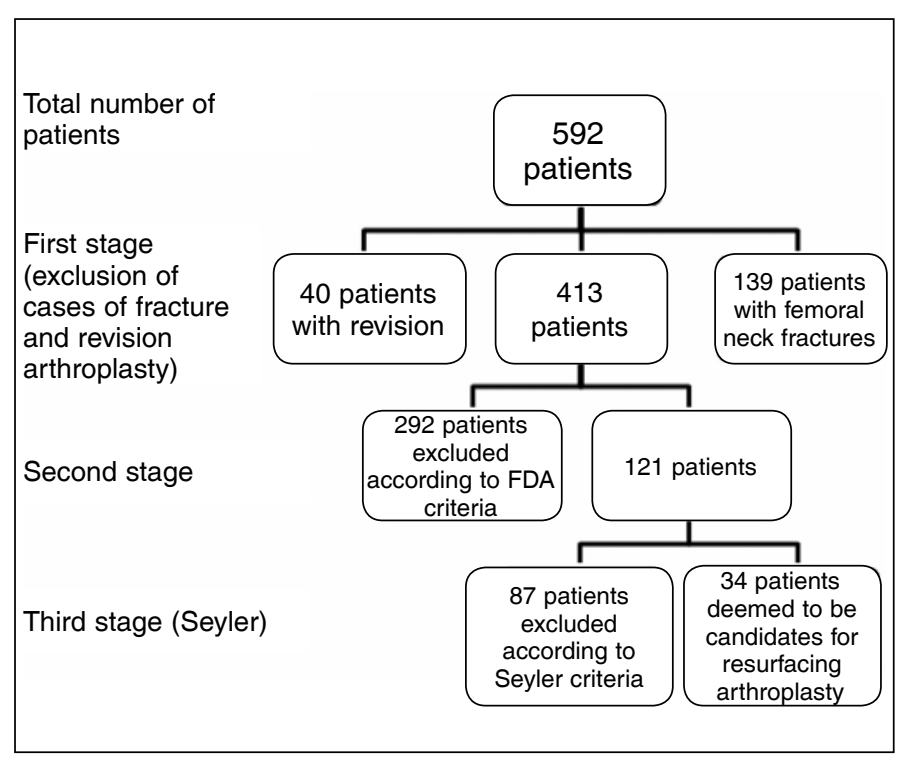

Figure 3 - Patients assessed through the three stages of the study and final candidates for resurfacing.

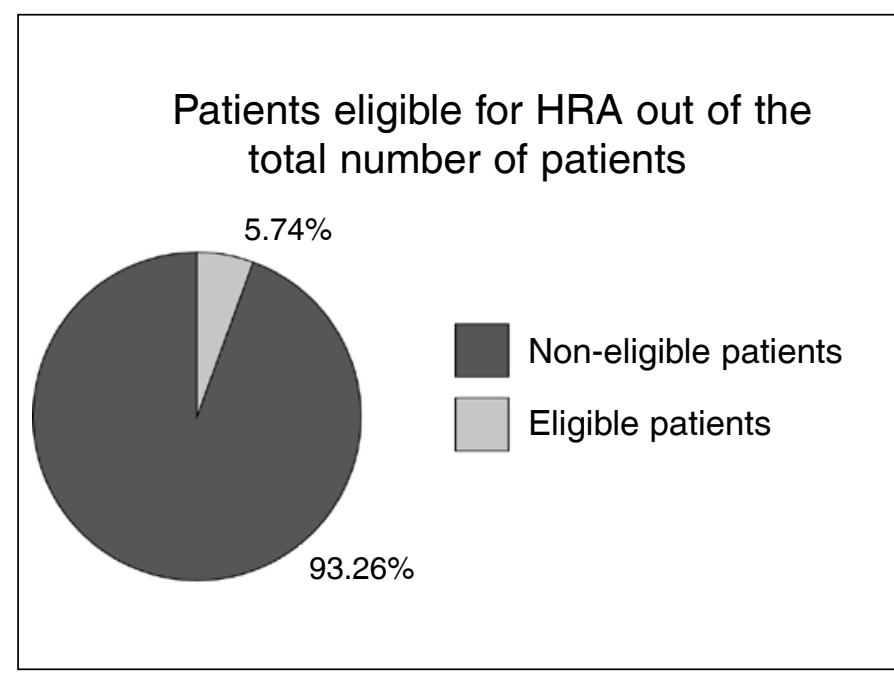

Figure 4 - Patients eligible for HRA out of the total number of patients who underwent replacement arthroplasty at HSPE between January 2009 and December 2010.

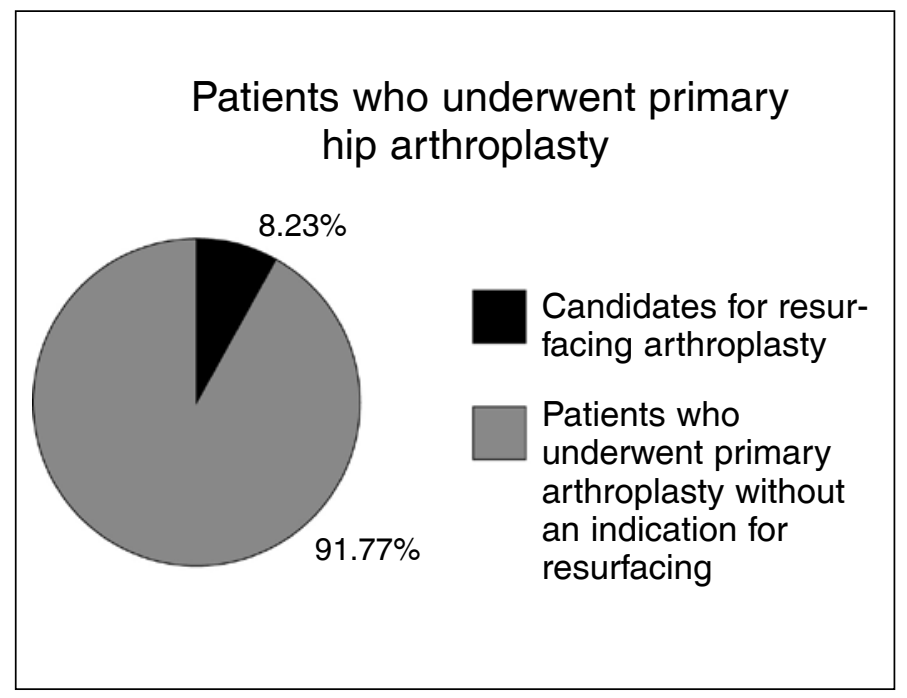

Figure 5 - Percentage indication of HRA out of the primary hip arthroplasties performed.

\section{DISCUSSION}

Resurfacing arthroplasty emerged over the last few years. Alongside this growth, the numbers of published papers and controversies also grew. Despite the published data, it remains unclear which candidates are best for this technique and what the absolute and relative contraindications are ${ }^{(1)}$.

The demand for HRA has been increasing recently, both from patients and from hip surgeons. Before May 2006, when the FDA approved the first resurfacing method, using metal-to-metal surfaces, only a small group of surgeons in the United States was authorized to perform resurfacing ${ }^{(17-20)}$. The main restrictions laid down by the FDA relate to the complications observed in the clinical studies that were conducted to gain approval for this type of implant, especially the large number of peri-implant fractures and excessive increases in metal levels in the blood ${ }^{(12)}$. Recently, the $\operatorname{FDA}^{(14,15)}$ determined that all manufacturers of prostheses with metal-to-metal contact surfaces should conduct studies on patients to ascertain whether they had high levels of metal ions in their organisms. It also communicated through its website that patients with certain resurfacing implants, from certain manufactures would be invited to undergo blood tests to assay the chromium and cobalt ion levels, and to undergo imaging examinations (magnetic resonance or ultrasound) to evaluate any occurrences of soft-tissue retraction, fluid accumulation or tumor formation. If present, revision surgery should be considered.

In relation to sex, the published studies are also contradictory regarding indications for this type of arthroplasty in women. Some studies have shown that femoral neck fractures occur more frequently in female patients who undergo HRA than among male patients $^{(20,21)}$, and that females present higher revision rates $^{(22)}$. Other studies, such as by Amstutz et al ${ }^{(23)}$, did not show any significant difference in the frequency of complications found in women, in relation to men.

There is also concern regarding the increased serum levels of metal ions caused by metal-to-metal prostheses, which are the only type of HRA prosthesis authorized by the FDA, including in relation to women of fertile age. There is clear evidence to sustain the notion that metal ion levels increase in patients who receive metal-to-metal prostheses ${ }^{(24-27)}$. Although there have already been studies suggesting that this does not have any consequences for the fetus and 
that the placenta may function as a selective barrier against these ions ${ }^{(24,28)}$, there is still a lack of studies proving this. Therefore, this possibility should still be taken into account in the exclusion criteria for selecting patients to be candidates for HRA.

Comparisons in the literature between resurfacing and conventional total arthroplasty, in similar groups of patients, with procedures performed by experiences and capacitated surgeons, show that over the short term, there are no great differences between the two procedures. Sandiford et $a l^{(29)}$ compared groups of young and active patients who underwent uncemented total hip arthroplasty or resurfacing arthroplasty in order to deal with their complaints and functional demands, with a short clinical follow-up. These authors concluded that the patients did not present any significant difference in relation to either postoperative satisfaction or functional demand. Fowble et $a l^{(30)}$ also compared the two techniques and concluded that there were no significant differences in the clinical results. However, conventional total hip arthroplasty presented shorter duration of surgery, with a mean of 148 minutes, versus 174 minutes, and complete pain relief in $80 \%$ of the patients, while resurfacing presented $48 \%$. On the other hand, the patients who underwent resurfacing presented less bleeding during the operation and immediately afterwards, via vacuum drainage. Marker et $a l^{(31)}$ conducted a review of the literature and compared studies on total hip arthroplasty and resurfacing with regard to basic science, radiographic criteria and clinical issues. These authors also concluded that in the literature, no advantages were shown for one procedure in relation to the other. With regard to radiographic characteristics, such as the positions of the components and correction of the offset, conventional arthroplasty presents a relative advantage. In addition, the length of follow-up in studies on resurfacing was shorter than in studies on total hip arthroplasty.

Regarding the patients' ages, there is a consensus in the literature in relation to the concept that the older the patient is, the greater the risk of early revision following resurfacing arthroscopy becomes. According to data from the National Joint Replacement Registry of the Australian Orthopaedic Association, in its 2008 Annual Report ${ }^{(21)}$, the revision rates over the first five postoperative years were $3.1 \%$ among patients under the age of 55 years, $4.1 \%$ between 55 and 64 years, 5\% between 65 and 74 years and 9.9\% among patients over the age of 75 years. Today, many authors contraindicate HRA in male patients over the age of 65 years $^{(32-34)}$.

From a review of the literature and clinical studies, Seyler et $a l^{(1)}$ proposed an algorithm to facilitate indications for resurfacing and decisions on patient eligibility. Application of this algorithm allows standardization of patient selection, both for novice and for experienced surgeons, and has the aim of reducing the complications associated with this procedure. Selecting a technique that is associated with better patient indication is reflected in better clinical results. In the survey conducted at HSPE, this algorithm was used on the patients who underwent hip arthroplasty in 2009 and 2010, and the criteria for absolute contraindication according to the FDA were also taken into consideration. Seyler et $a l^{(1)}$ recommended that surgeons should assess the characteristics of the acetabulum and femoral neck, which may influence the technical aspects of the resurfacing process and consequently the survival of the implant.

Because resurfacing is still a little-used procedure in Brazil, few clinics are capacitated to perform it. In a study with level II evidence, Nunley et $a l^{(7)}$ determined the learning curve associated with resurfacing. They compared the rate of early complications from resurfacing procedures among the first 650 hips operated by five experienced surgeons and a national database. They concluded that for experienced hip surgeons, the learning curve for avoiding early clinical complications was approximately 25 cases. However, even so, they presented unsatisfactory implant positioning and radiographic findings. The learning curve for experienced surgeons to achieve the desired positioning of components, assessed radiographically, was much longer: 75 to 100 cases or more.

In the survey conducted at HSPE, even though the volume of surgical cases was relatively large in relation to other Brazilian clinics, the number of cases eligible for resurfacing during the years 2009 and 2010 was 34 patients, i.e. approximately two years of training for an experienced surgeon. In another study conducted by O'Neill et al(35), it was found that the complication rate from the initial cases of resurfacing arthroplasty was not unacceptably high in any of the academic centers in Canada in 2007. It is important to emphasize that in their study, all the surgeons 
involved were hip specialists and were considered to be experienced, with large volumes of surgical cases. As with any new technique, patient selection is fundamentally important, and the indications need to be precise. Although studies on a single experienced surgeon with a large volume of surgical cases have shown results comparable with those from total hip arthroplasty, four recent multicenter studies reported failure rates from resurfacing of 6 to $7.4 \%$, over a short follow-up period ${ }^{(36-39)}$. Thus, the learning curve associated with resurfacing might be considered to be excessively steep to justify offering this as a safe and effective means of treating hip arthrosis, especially if the surgeon is inexperienced. However, this argument has left some unanswered questions regarding the role of resurfacing in treating hip arthrosis. Hence, it is important to analyze the number of cases with an indication for this treatment and the learning curve for this procedure in a group of surgeons without previous training, but with significant experience of hip arthroplasty. In this case, at the Hip Surgery Clinic of HSPE, among the patients selected after using the algorithm, the learning curve and particularly its length would be relatively long.

Regarding the rate of use of the HRA technique, it accounted for around 8\% of the primary hip arthroplasty procedures performed in Australia in 2007, and it has been found to range between 6 and $9 \%$ in Europe, i.e. similar to the results obtained in the present study. The Australian registry indicates that there is greater risk of early revision after resurfacing, during the first six to 12 months after the operation ${ }^{(12)}$. However, after the first postoperative year, the revision rates do not differ between resurfacing and conventional arthroplasty when the patients are adequately selected. These high revision rates during the first 12 months are considered to be related to the surgical technique and to the precision of component positioning ${ }^{(12)}$.

\section{CONCLUSION}

The surgeon's experience and precise selection of patients continue to be key factors for success in this procedure. The importance of selecting the patients must not be underestimated, especially for surgeons who are at the start of the learning curve. The algorithm used here can be used to standardize patient selection and obtain better results. In our study, this type of surgery was shown to still have a limited role among hip surgery methods.

\section{REFERENCES}

1. Seyler TM, Marker DR, Boyd HS, Zywiel MG, McGrath MS, Mont MA. Preoperative evaluation to determine candidates for metal-on-metal hip resurfacing. J Bone Joint Surg Am. 2009;91(Suppl 6):32-41.

2. Amstutz HC, Ball ST, Le Duff MJ, Dorey FJ. Resurfacing THA for patients younger than 50 year: results of 2- to 9-year followup. Clin Orthop Relat Res. 2007;(460):159-64.

3. Amstutz HC, Campbell PA, Le Duff MJ. Fracture of the neck of the femur after surface arthroplasty of the hip. J Bone Joint Surg Am. 2004;86(9):1874-7

4. Beaulé PE, Dorey FJ, Le Duff MJ, Gruen T, Amstutz HC. Risk factors affecting outcome of metal-on-metal surface arthroplasty of the hip. Clin Orthop Relat Res. 2004;(418):87-93.

5. Boyd HS, Ulrich SD, Seyler TM, Marulanda GA, Mont MA. Resurfacing for Perthes disease: an alternative to standard hip arthroplasty. Clin Orthop Relat Res. 2007;465:80-5.

6. McMinn D, Daniel J. History and modern concepts in surface replacement. Proc Inst Mech Eng H. 2006;220(2):239-51.

7. Nunley RM, Della Valle CJ, Barrack RL. Is patient selection important for hip resurfacing? Clin Orthop Relat Res. 2009;467(1):56-65.

8. Morlock MM, Bishop N, Rüther W, Delling G, Hahn M. Biomechanical, morpho- logical, and histological analysis of early failures in hip resurfacing arthroplasty. Proc Inst Mech Eng H. 2006;220(2):333-44.

9. Radcliffe IA, Taylor M. Investigation into the effect of varus-valgus orientation on load transfer in the resurfaced femoral head: a multi-femur finite element analysis. Clin Biomech (Bristol, Avon). 2007;22(7):780-6.

10. Shimmin AJ, Back D. Femoral neck fractures following Birmingham hip resurfacing: a national review of 50 cases. J Bone Joint Surg Br. 2005;87(4):463-4.

11. Shimmin AJ, Bare J, Back DL. Complications associated with hip resurfacing arthroplasty. Orthop Clin North Am. 2005;36(2):187-93.

12. Nunley RM, Zhu J, Brooks PJ, Engh CA Jr, Raterman SJ, Rogerson JS,et al. The learning curve for adopting hip resurfacing among hip specialists. Clin Orthop Relat Res. 2010;468(2):382-91.

13. Singh M, Nagrath AR, Maini PS. Changes in trabecular pattern of the upper end of the femur as an index of osteoporosis. J Bone Joint Surg Am. 1970;52(3):457-67.

14. FDA: U.S. Food and Drug Administration: CDRH Consumer Information for Hip Resurfacing. Birmingham Hip Resurfacing (BHR) System. Available at http:// www.fda.gov/MedicalDevices/ProductsandMedicalProcedures/DeviceApprovalsandClearances/Recently-ApprovedDevices/ucm078189.htm. 
15. FDA: U.S. Food and Drug Administration: CDRH Consumer Information for Hip Resurfacing. Cormet Hip Resurfacing System. Available at http://www.fda.gov/ MedicalDevices/ProductsandMedicalProcedures/DeviceApprovalsandClearances/Recently-ApprovedDevices/ucm076954.htm.

16. Mortazavi SMJ, Fertala K, Restrepo C, Parmar R, Hozack WJ. Patient selection for resurfacing hip arthroplasty a matched case study of resurfacing hip arthroplasty versus total hip arthroplasty. Techn Orthop. 2010;25(1):2-7.

17. Amstutz HC, Beaulé PE, Dorey FJ, Le Duff MJ, Campbell PA, Gruen TA. Metalon-metal hybrid surface arthroplasty: two to six-year follow-up study. J Bone Joint Surg Am. 2004;86(1):28-39.

18. Amstutz HC, Grigoris P, Dorey FJ. Evolution and future of surface replacement of the hip. J Orthop Sci. 1998;3(3):169-86.

19. Beaulé PE, Le Duff M, Campbell P, Dorey FJ, Park SH, Amstutz HC. Metal-onmetal surface arthroplasty with a cemented femoral component: a 7-10 year follow-up study. J Arthroplasty. 2004;19(8 Suppl 3):17-22.

20. Schmalzried TP, Fowble VA, Ure KJ, Amstutz HC. Metal on metal surface replacement of the hip. Technique, fixation, and early results. Clin Orthop Relat Res. 1996;(329 Suppl):S106-14.

21. National Joint Replacement Registry of the Australian Orthopaedic Association. Annual Report 2008. Disponível em: http://www.dmac.adelaide.edu.au/aoanjrr/ publications.jsp?section=reports2008. Accessed 2009 Sep 8.

22. Jameson SS, Langton DJ, Natu S, Nargol TV. The influence of age and sex on early clinical results after hip resurfacing: an independent center analysis. J Arthroplasty. 2008;23(6 Suppl 1):50-5.

23. Amstutz HC, Wisk LE, Le Duff MJ. Sex as a patient selection criterion for metal-on-metal hip resurfacing arthroplasty. J Arthroplasty. 2011;26(2):198-208.

24. Brodner W, Grohs JG, Bancher-Todesca D, Dorotka R, Meisinger V, Gottsauner-Wolf $F$, et al. Does the placenta inhibit the passage of chromium and cobalt after metal-on-metal total hip arthroplasty? J Arthroplasty. 2004;19(8 Suppl 3):102-6.

25. MacDonald SJ. Can a safe level for metal ions in patients with metal-on-metal total hip arthroplasties be determined? J Arthroplasty. 2004;19(8 Suppl 3):71-7.

26. MacDonald SJ. Metal-on-metal total hip arthroplasty: the concerns. Clin Orthop Relat Res. 2004;(429):86-93.
27. MacDonald SJ, Mehin R. Metal on metal: Clinical results with modern implants. Semin Arthroplasty. 2003;14:123-30.

28. Ziaee H, Daniel J, Datta AK, Blunt S, McMinn DJ. Transplacental transfer of cobalt and chromium in patients with metal-on-metal hip arthroplasty: a controlled study. J Bone Joint Surg Br. 2007;89(3):301-5.

29. Sandiford NA, Muirhead-Allwood SK, Skinner JA, Hua J. Metal on metal hip resurfacing versus uncemented custom total hip replacement--early results. J Orthop Surg Res. 2010;5:8.

30. Fowble VA, dela Rosa MA, Schmalzried TP. A comparison of total hip resurfacing and total hip arthroplasty - patients and outcomes. Bull NYU Hosp Jt Dis. 2009;67(2):108-12.

31. Marker DR, Strimbu K, McGrath MS, Zywiel MG, Mont MA. Resurfacing versus conventional total hip arthroplasty - review of comparative clinical and basic science studies. Bull NYU Hosp Jt Dis. 2009;67(2):120-7.

32. Daniel J, Pynsent PB, McMinn DJ. Metal-on-metal resurfacing of the hip in patients under the age of 55 years with osteoarthritis. J Bone Joint Surg Br. 2004;86(2):177-84.

33. De Smet KA. Belgium experience with metal-on-metal surface arthroplasty. Orthop Clin North Am. 2005;36(2):203-13.

34. Hing C, Back D, Shimmin A. Hip resurfacing: indications, results, and conclusions. Instr Course Lect. 2007;56:171-8.

35. O'Neill M, Beaule PE, Bin Nasser A, Garbuz D, Lavigne M, Duncan C, et al. Canadian academic experience with metal-on-metal hip resurfacing. Bull NYU Hosp Jt Dis. 2009;67(2):128-31.

36. Kim PR, Beaulé PE, Laflamme GY, Dunbar M. Causes of early failure in a multicenter clinical trial of hip resurfacing. J Arthroplasty. 2008;23(6 Suppl 1):44-9.

37. Della Valle CJ, Nunley RM, Raterman SJ, Barrack RL. Initial American experience with hip resurfacing following FDA approval. Clin Orthop Relat Res. 2009;467(1):72-8.

38. Siebel T, Maubach S, Morlock MM. Lessons learned from early clinical experience and results of 300 ASR hip resurfacing implantations. Proc Inst Mech Eng H. 2006;220(2):345-53.

39. Mont MA, Seyler TM, Ulrich SD, Beaule PE, Boyd HS, Grecula MJ, et al. Effect of changing indications and techniques on total hip resurfacing. Clin Orthop Relat Res. 2007;465:63-70. 